\title{
Information and Communication Technology and the Development of Digital Trade
}

\author{
Na Jiang \\ School of Economics, Shanghai University, Shanghai, China \\ 234117612@qq.com
}

Keywords: information and communication technology, digital trade, rules of digital trade

Abstract: In the rapid development of Internet technology and electronic commerce, major changes have taken place in international trade subject, trade form, business model and organization mode. The global digital trade is flourishing, with vigorous vitality and broad prospects for development. It also brings great impact and challenge to the international trade system mechanism, rule system, supervision and law enforcement, which is based on traditional trade. At present, there are "American templates" and "European templates" in the formulation of global digital trading rules. As the core of the global trading system, WTO still has great potential in dealing with global digital trade governance.

\section{Introduction}

In recent years, the global digital trade has developed vigorously, and it has vigorous vitality and broad prospects for development. In the entertainment industry, digital trade accounts for more than $50 \%$ of music sales, $40 \%$ of game sales, $30 \%$ of video content consumption, and $20 \%$ of book purchases. Governments have begun to pay attention to the development of digital economy, and regard digital economy as a new engine to promote economic development. The United States takes the lead in releasing the first digital trade research report, "digital trade in the United States and the global economy". The European Parliament's International Trade Commission approved the adoption of the digital trade strategy report in November 2017 to promote the establishment of the EU's data trade strategy.

Digital trade is a new trade form relying on information and communication technology. In response to this new form of challenge, the United States has been trying to set a binding global standard for digital trade in its dominant regional trade arrangements. The EU also has its own demands for the formulation of digital trade rules. As the most efficient multilateral trade governance institution in the world, WTO has submitted proposals for several years by the main members of WTO, showing the core demands and important concerns in the construction of the system of digital trade governance. 


\section{Overview of Digital Trade}

\subsection{Related Concepts}

Information and communication technology (ICT) is an encompassing term covering all communication devices or applications and all kinds of services and applications related to them, such as video conferencing and remote teaching.

Digital trade refers to, relying on the Internet as the basis, using digital exchange technology as a means to provide the supply and demand parties with the exchange of digital electronic information needed to achieve the digital information as a trade standard, innovative business model.

In July 2013, the United States International Trade Commission reported the concept of digital trade in the United States and the global economy, that is, the commercial activities of products and services carried out through the Internet, including the commercial activities of domestic products and services through the Internet, as well as through the Internet. International trade in the transmission of products and services.

Digital trade has the following elements: first, it is based on the Internet, using digital exchange technology as a means, transmission through the Internet as the medium; secondly, it provides the digital data information needed for the interaction between the supply and demand parties, and realizes the trade mark with the digital data information; finally, the digital trade is different from the traditional trade. It is an innovative business model, which includes both digital products and digital services.

According to the definition of the United States, digital trade can be divided into 4 categories, shown in Table 1.

Table 1 Basic Classification of Digital Trade

\begin{tabular}{|c|c|}
\hline Basic Classification & Concrete Content \\
\hline digital content & digital music; digital games; digital video; digital books \\
\hline social media & social networking sites; user reviews website \\
\hline search engines & general search engine; professional search engine \\
\hline $\begin{array}{c}\text { other products and } \\
\text { services }\end{array}$ & $\begin{array}{c}\text { software service; data services provided through } \\
\text { cloud computing ;communication services provided } \\
\text { through the Internet; computing platform services } \\
\text { through cloud computing }\end{array}$ \\
\hline
\end{tabular}

\subsection{The Characteristics of Digital Trade}

Compared with traditional trade, digital trade has notable characteristics.

First of all, the efficiency of digital trade is high. Digital trade is based on the Internet, using digital exchange technology as a means and using the Internet as the medium. It not only changes the way of production and delivery of many goods and services, but also directly shortens the distance of time and space, reduces transaction costs and improves efficiency. The result is an optimization of the trading system, streamlining the trade process and increasing trade opportunities.

Secondly, digital trading objects have the characteristics of high knowledge, high technology, high interaction and high innovation. The services provided by digital trade to customers are knowledge intensive, not other general services. It emphasizes interaction with customers through high interaction. Moreover, as customers' innovative collaborators, they play multiple roles as promoters, disseminators and initiators in the process of innovation.

Finally, new forms of digital trade are emerging. The development of new technologies, such as 
cloud computing, large data, mobile Internet, social media, not only expands the range of digital trade product services, but also adapts and stimulates the special personality needs of customers, and meets the needs of real-time, interactivity, low cost and individualization.

\section{The Development Prospect and Main Restrictions of Digital Trade}

\subsection{The Development Prospect of Digital Trade}

Digital technology is changing the way business and international trade operate. The expansion of the network infrastructure has contributed to the creation of a large number of devices, cloud services and data analysis resources, and has been used by many companies. As the expansion of the network reduces the cost, it also greatly improves the access speed of the Internet, so many new (and affordable) devices have been able to use higher available bandwidth to collect and transmit more data. At the same time, the expansion of the capacity of the Internet infrastructure and the enhancement of the technical functions have also enabled the growth of cloud services to be realized, shown in Table 2.

Table 2 Public Cloud Service Expenditure in 2016(Unit: million dollars per year)

\begin{tabular}{|c|c|c|c|c|c|c|}
\hline Cloud service & U.S. & EU & Brazil & Russia & China & India \\
\hline Saas & 46,428 & 12,702 & 440 & 275 & 804 & 402 \\
\hline Iaas & 8,076 & 4,007 & 262 & 83 & 1,427 & 229 \\
\hline Paas & 8,193 & 2,325 & 143 & 32 & 75 & 61 \\
\hline Total & 62,698 & 19,034 & 845 & 390 & 2,307 & 692 \\
\hline
\end{tabular}

Source: Internet Data Center (IDC), March 2017

The rapid growth of network communication services and networking devices has opened up a new way for communication and data collection. The interaction between people (for business or personal use) through convenient voice, video, and other services is the embodiment of this trend, as is the use of smartphones, tablets, wearable devices and telemedicine devices. In addition, through the network of "smart home" and "smart city", consumers and urban public facilities can monitor and even adjust home or city equipment.

\subsection{Main Restrictions}

Although the capacity of cloud computing data processing and analysis has developed in many markets, some countries have developed regulatory and policy measures to mitigate or stop the use of digital technology and digital trade at home.

- The localization of digital trade. Different countries have taken or formulated measures to protect privacy or safeguard the security of the system, requiring all companies to localization the data server in accordance with the policy. This is the main obstacle.

- Network security and data privacy protection. American industry representatives are also worried about network security restrictions in many countries. They believe that two restrictions may seriously impede the development of digital trade, one is open source code, and the other is to restrict the use of encryption.

- The protection of intellectual property rights. If the law of a country is weak in the protection of intellectual property rights, or ineffective protection of intellectual property rights, it may lead to a wide range of pirated digital products, so it is difficult for network content providers to profit from their legitimate marketing channels.

- The content review. For the sake of public interest, some governments have adopted content 
censorship measures to prevent some Internet content from accessing their networks. Content review policy has affected quite a number of web content providers, including news, video and social media services.

- Market access. Among them, several important measures include the "micro allowance", the electronic payment system, the technical standard and the government procurement.

- Investment. Policies that affect the overseas investment of digital trading companies include foreign equity ratio restrictions, discriminatory licensing, tax policies and local content requirements.

\section{Construction of Multilateral Digital Trade Rules}

Digital trade has brought great challenges to the traditional international trade system, rules and regulations, supervision and law enforcement. To effectively resolve the obstacles and barriers to digital trade and promote the long-term and stable development of digital trade, it is urgent to push forward the multilateral trade rules for digital trade and build a multilateral system of digital trade rules.

\subsection{Regional Digital Trade Arrangement of U.S}

As the leader of world digital trade, the United States promotes the consistent commitment of cross-border data flow and digital trade in TPP, TTIP and TISA, and promotes the construction of international rules for digital trade. It is aimed at further strengthening the role of digital trade as the pole of economic growth, consolidating and expanding its competitive advantage and position in digital trade, leading the development of digital trade in the world and opening up a new market for national digital trade.

The United States regards the TPP negotiations as the most important forum for achieving a consistent commitment to digital trade and cross-border data flows to achieve the goal of achieving a consistent commitment to digital trade and cross-border data flows as the core standard for the success of the negotiation of a cross Pacific Partnership Agreement (TPP) negotiation. It creates an important precedent for the discussion of Digital Trade and cross-border data flows in the cross the Atlantic trade and investment partnership agreement (TTIP). In the service trade agreement (TISA), they expect to establish regulation rules in emerging fields such as electronic commerce, computer related news and cross-border data transfer, and emphasize the formulation of appropriate provisions to support trade in services through "electronic channels" and to guide the development of digital and cross-border data flows.

\subsection{The EU's Target of Digital Trade Rules}

Overall, the "European template" of the digital trading rules is still in its infancy, and the relevant regulations are scattered in different chapters. In the negotiations on the rules of digital trade, the EU's most concerns are mainly focused on the "free flow of cross-border data", "intellectual property protection" and "audio-visual cooperation". However, the EU itself has an impenetrable red line through the "privacy protection" and "audio-visual exception", which leads to the difficult progress of the EU and the digital trading countries in many departments.

\subsection{WTO's Global Digital Trade Governance}

As the core of the multilateral trading system, WTO has been unable to fulfil the global digital trade governance function in recent years. However, as the WTO system itself has strong capability of repair and transformation, it still has considerable potential to participate in and even dominate 
global digital trade governance in the future. According to a series of recent proposals submitted by the main members of the WTO, and in conjunction with the legislation of the WTO members themselves and the case practice of the WTO dispute settlement mechanism. WTO will strive to build and transform the multilateral digital trade system from the aspects of ITA protocol expansion, upgrading of TRIPS, the construction of new cross-border data flow coordination mechanism, the rational definition and interpretation of the GATS rules and the scope of the application of commitments at this stage.

United States International Trade Commission Digital Trade in the U.S. and Global Economies, Part 1, July 2013.

\section{References}

[1] International Telecommunications Union(ITU).2014. “ICT Facts and Figures2014.”[ EB/ OL] https :// www.itu.int /en/ITU-D/Statistics /Documents/facts/ICTFactsFigures2014-e.pdf .

[2] Anupam Chander,DATA NATIONALISM,2015,Emory Law Journal, 64 Emory L.J.677

[3] ALBRIGHT STONEBRIDGE GROUP.Data Localization: A Challenge to Global Commerce[R].Washington, DC: Albright Stonebridge Group, 2015.09.

[4] MCKINSEY GLOBAL Institute.Digital Globalization: The New Era of Global Flows[R].New York: McKinsey Global Institute, 2016.03.

[5] Amy Porges, Alice Enders.Data Moving across Borders: The Future of Digital Trade Policy [J].International Center for Trade and Sustainable Development, 2016.

[6] Joshua P.Meltzer.2016.Maximizing the Opportunities of the Internet for International Trade[J].Social Science Electronic Publishing .

[7] Fleuter S.The Role of Digital Products under the WTO: A New Framework for GATT and GATS Classification [J].Chicago Journal of International Law, 2016, 17.

[8] Burri M.The Regulation of Data Flows through Trade Agreements [J]. Social Science Electronic Publishing, 2017, 48(1):407 - 448 . 